\title{
Molecular Epidemiology and Antimicrobial Resistance of Campylobacter coli from Caeca and Carcass of Poultry in Lebanon
}

\section{Sukayna M Fadlallah ${ }^{1}$, Rima El Hajj ${ }^{2}$, Jeanne El Hage ${ }^{2}$, Zeina Nasser ${ }^{3}$, Nada Ghosn $^{3}$, Walid Ammar ${ }^{3}$ and Ghassan M Matar ${ }^{1 *}$}

${ }^{1}$ American University of Beirut, Beirut, Lebanon

${ }^{2}$ Lebanese Agriculture Research. Institute, Fanar, Lebanon

${ }^{3}$ Ministry of Public Health, Beirut, Lebanon

*Corresponding Author: Ghassan M Matar, Department of Experimental Pathology, Immunology and Microbiology, Faculty of Medicine, American University of Beirut, Beirut, Lebanon.

Received: February 09, 2018; Published: March 22, 2018

DOI: $10.31080 /$ ASMI.2018.01.0040

\begin{abstract}
Campylobacter is the primary bacterial cause of human intestinal infections worldwide. Species identification of fifty one Campylobacter positive isolates collected at two slaughterhouses in Lebanon was done using the $16 \mathrm{~S}$ rRNA sequencing. Antimicrobial susceptibility testing (AST) was performed using a wide range of $\beta$ lactam agents and tetracycline. Polymerase chain reactions (PCR) detection of the $b l a_{\mathrm{OXA}-61}$ and tet(0) genes in resistant and susceptible isolates to ampicillin and tetracycline respectively was determined. Genomic diversity of the isolates was assessed using Random Amplified Polymorphic DNA (RAPD). Sequencing analysis revealed that all tested isolates were Campylobacter coli. AST showed resistance in the isolates to cephalothin and aztreonam (100\%), cefamandole and cefoxitin (98\%), tetracycline (94\%), ampicillin (49\%), amoxicillin (47\%), piperacillin (45\%), carbenicillin (37\%), ticarcillin (20\%), ceftazidime (18\%), cefotaxime (8\%) and amoxicillin-clavulanic acid (2\%). All ampicillin-resistant isolates and $84 \%$ of the ampicillin-sensitive ones carried the $b l a_{\mathrm{OXA}-61}$ gene. All tetracycline-resistant isolates were positive for the tet(0) gene with $98 \%$ encoded on plasmids. RAPD analysis revealed nine distinct clusters with a minimum percentage of $43.5 \%$ genomic similarity. This study emphasizes the importance of surveillance in identifying and controlling commonly circulating food borne pathogens.
\end{abstract}

Keywords: Campylobacter; Antimicrobial Resistance; Sequencing; Random Amplified Polymorphic DNA (RAPD); Lebanon; Poultry

\section{Abbreviations}

AST: Antimicrobial Susceptibility Testing; BLAST: Basic Local Alignment Search Tool; C. coli: Campylobacter coli; C. jejuni: Campylobacter jejuni; Exo: Exonuclease I; fla typing: Flagellin Typing; LARI: Lebanese Agriculture Research Institute; MoPH: Ministry of Public Health; PCR: Polymerase Chain Reactions; PFGE: PulsedField Gel Electrophoresis; RAPD: Random Amplified Polymorphic DNA; RFLP: Restriction Fragment Length Polymorphism; SAP: Shrimp Alkaline Phosphatase; UPGMA: Unweighted Pair Group Method Using Arithmetic Averages

\section{Introduction}

Campylobacter is the primary cause of human intestinal infections of bacterial origin worldwide (EFSA, 2013). Campylobacter spp. are commonly isolated from the intestinal tract of domestic and wild animals such as pigs, cows, poultry, dogs, cats, hamsters, and others (Lehtopolku, 2011). Presently, 17 species and six subspecies of Campylobacter have been identified; $C$. jejuni and $C$. coli being the most commonly reported species in human diseases (WHO, 2011). These species can be differentiated using a wide range of conventional methods such as growth temperature, cephalothin and na- lidixic acid susceptibility, hippurate hydrolysis, and biochemical tests. In addition, alternative methods of differentiation include API Campy, mass spectrometry, and molecular methods such as Polymerase chain reaction (PCR) assays or sequencing using the 16S rRNA gene (Martiny et al., 2011).

Campylobacter species are usually susceptible to a wide range of antimicrobial agents such as macrolides, fluoroquinolones, tetracycline, and aminoglycosides making them the drug of choice for severe cases of human infections (Lehtopolku, 2011). Nonetheless, resistance to antimicrobial agents has been emerging especially to fluoroquinolones such as ciprofloxacin and macrolides such as erythromycin (Bae et al., 2005; Lehtopolku, 2011; Vlieghe, et al., 2008). A significant rise in resistance to tetracycline was also observed in Campylobacter isolates from fowl, broiler meat, pigs and cattle (EFSA, 2012). This resistance is encoded mostly by a chromosomal or plasmid borne gene, tet(0). The plasmid borne gene is widespread and has a high rate of conjugation making tetracycline resistance common (Taylor, 1988). Although ampicillin is not considered to be the drug of choice for Campylobacter infections, a large number of Campylobacter strains produce $\beta$-lactamases and these strains have been shown to be more resistant to amoxicil- 
lin, ampicillin, and ticarcillin than $\beta$-lactamases negative strains. This is due to the presence of a gene carried by the Campylobacter chromosome called bla $_{\mathrm{OX}-61}$ which encodes an amino acid putative periplasmic class D $\beta$-lactamase, Cj0299 (Griggs et al., 2009; Parkhill et al., 2000).

The diversity within Campylobacter spp. can be detected using a wide range of phenotypic typing such as phage typing and genotypic methods namely Pulsed-Field Gel Electrophoresis (PFGE), Random Amplified Polymorphic DNA (RAPD), Restriction Fragment Length Polymorphism (RFLP), flagellin typing (fla typing), and ribotyping (Wassenaar and Newell, 2000 ; Nielsen et al., 2000). The genotypic methods usually have a higher discriminatory power and are more efficient in detecting outbreaks (Nielsen et al., 2000).

In Lebanon, Campylobacter can be under-detected since it is not part of routine stool culture. Additionally, very few studies have been conducted on Campylobacter spp. isolated from animals and humans. A study by Talhouk., et al. (1998) showed that out of 281 diarrheic stool specimens, 150 caeca, and 31 chicken carcasses collected in Lebanon, $0.7 \%$ of human stool specimens, $22.7 \%$ of the ceca samples and $9.7 \%$ of the chicken carcasses were Campylobacter positive. Hence, due to scarcity of studies in Lebanon on Campylobacter, the aims of this study were to: assess the prevalence of Campylobacter spp. in chicken carcass and caeca collected at two slaughterhouses in Lebanon, identify the isolates to the species level, evaluate the antimicrobial resistance to a number of $\beta$-lactam agents and tetracycline, and determine genomic variation.

\section{Materials and Methods}

\section{Bacterial isolates}

Campylobacter isolates were obtained from the Lebanese Agriculture Research Institute (LARI) through the Ministry of Public Health (MoPH). The samples were collected at two slaughterhouses that receive broiler meat from different owners and were of two types: chicken caeca samples taken during the evisceration process and whole poultry carcass. Twenty-six batches of chickens were collected and tested for the presence of Campylobacter spp.; each comprising one carcass taken at the end of the processing line and several caecal samples randomly collected from 5 to 10 birds. Detection of Campylobacter was performed according to the ISO 10272: 2006 standard.

\section{DNA extraction}

Genomic and plasmid borne DNA were extracted using a Qiamp DNA mini kit (Qiagen, Hilden, Germany) and QIAprep Spin Miniprep Kit (Qiagen, Hilden, Germany) respectively according to the manufacturer's instructions.

\section{Species Identification}

Polymerase Chain reaction (PCR): The primers used in the amplification were 27Forward and 519Reverse for the 16S rRNA gene according to Lane., et al. (1991) and Turner., et al. (1999) respectively (Sigma Aldrich, Missouri, United States). Each reaction assay $(20 \mu \mathrm{l})$ contained the following: $500 \mu \mathrm{M}$ dNTPs, $\times 1$ Taq buffer, 2.5 $\mathrm{mM} \mathrm{MgCl}, 0.4 \mu \mathrm{M}$ of each primer, $0.1 \mathrm{U}$ of Taq polymerase, and genomic DNA with a minimal concentration of $20 \mathrm{ng}$. The cycling conditions were as follows: initial denaturation at $95^{\circ} \mathrm{C}$ for 12 minutes, 30 cycles of: $94^{\circ} \mathrm{C}$ for 30 seconds, $53^{\circ} \mathrm{C}$ for 30 seconds and $72^{\circ} \mathrm{C}$ for
1 minute, and a final extension cycle at $72^{\circ} \mathrm{C}$ for 10 minutes. The amplicons were subsequently purified using a combination of Exonuclease (Exo) I and Shrimp Alkaline Phosphatase (SAP) (Thermoscientific, Ulm, Germany): $1 \mu \mathrm{l}$ of SAP enzyme and $0.5 \mu$ l of Exonuclease I (Exo) enzyme added to $6 \mu \mathrm{l}$ of PCR product. Consequently, the purified amplicons (502bp) were analyzed on a $1.5 \%$ agarose gel run at $120 \mathrm{~V}$ for 45 minutes.

Sequencing: Sequencing analysis was done using the Big Dye Terminator 2.0 kit (Applied Biosystems, California, United States) according to the manufacturer's instruction. Species identification of the Campylobacter isolates was determined using the Basic Local Alignment Search Tool (BLAST).

\section{Antimicrobial susceptibility testing}

Antimicrobial susceptibility testing (AST) was performed following the Clinical and Laboratory Standards Institute guidelines (CLSI) using the Kirby-Bauer method on Mueller Hinton II agar plates with 5\% blood (CLSI, 2009). The antibiotics used were: (Oxoid, Hampshire, England) ampicillin, amoxicillin, carbenicillin, ticarcillin, piperacillin, amoxicillin with clavulanic acid, ceftazidime, cephalothin, cefamandole, cefotaxime, aztreonam, cefoxitin, and tetracycline. The Campylobacter jejuni ATCC 29428 strain was used as a quality control.

\section{Detection of resistance encoding genes}

PCR assay: The Taq PCR Master Mix kit (Qiagen, Hilden, Germany) was used to prepare the reaction mix according to the manufacturer's guidelines. A final reaction mix $(50 \mu \mathrm{l})$ consisted of buffer solution, $4 \mathrm{mM} \mathrm{MgCl}_{2}$, a $0.4 \mathrm{mM}$ of each dNTPs, and $0.05 \mathrm{u} / \mu \mathrm{L}$ Taq DNA polymerase, and genomic or plasmid borne DNA. The presence of the tet(O) (in both genomic and plasmid borne DNA) and blaOXA-61 genes, were detected using previously described primers [8], (Griggs et al., 2009; Pratt and Korolik, 2005). Cycling conditions of the tet(O) gene consisted of an initial denaturation at $94^{\circ} \mathrm{C}$ for 4 minutes, followed by 30 cycles of: $94^{\circ} \mathrm{C}$ for 30 seconds, $60^{\circ} \mathrm{C}$ for 1 minute and $72^{\circ} \mathrm{C}$ for 2 minutes, and a final extension at $72^{\circ} \mathrm{C}$ for 5 minutes. Whereas, the conditions of the $b l a_{\text {OXA61 }}$ gene were as follow: an initial denaturation at $94^{\circ} \mathrm{C}$ for 5 minutes, followed by 30 cycles of $94^{\circ} \mathrm{C}$ for 30 seconds, $56^{\circ} \mathrm{C}$ for 45 seconds and $72^{\circ} \mathrm{C}$ for 30 seconds, and a final extension at $72^{\circ} \mathrm{C}$ for 10 minutes. Consequently, Amplicons were detected on a $1 \%$ agarose gel run at $120 \mathrm{~V}$ for 45 minutes. The band sizes of the bla $_{\mathrm{OXA61}}$ and the $\operatorname{tet}(0)$ genes were $281 \mathrm{bp}$ and $559 \mathrm{bp}$ respectively.

\section{Random Amplified Polymorphic DNA (RAPD)}

RAPD analysis was carried out using the Ready-To-Go RAPD Analysis Beads Kit (GE, Amersham Place, United Kingdom) as per the manufacturer's instructions. The RAPD analysis primer 2 was provided by the kit and the cycling parameters were: 1 cycles of $95^{\circ} \mathrm{C}$ for 5 minutes, followed by 45 cycles of $95^{\circ} \mathrm{C}$ for 1 minute, $36^{\circ} \mathrm{C}$ for 1 minute and $72^{\circ} \mathrm{C}$ for 2 minutes. The resultant products were detected by gel electrophoresis, on a $2 \%$ agarose gel run for 3 hours at $150 \mathrm{~V}$. The dendrograms were generated using the UPGMA method (unweighted pair group method using arithmetic averages) with the BIONUMERICS software. 
Results

Among the samples submitted to analysis, 13 of 26 carcasses (50\%) and 38 of 104 caeca (37\%) were Campylobacter positive (n: 51); a total percentage of $39 \%$ positive samples. Moreover, five batches were Campylobacter positive in both the carcass and caeca samples corresponding to a specific batch. Sequence analysis revealed that all tested Campylobacter isolates were C. coli.

\section{Antibiotic resistance}

All isolates were resistant to cephalothin and aztreonam and 98\% showed resistance to cefamandole and cefoxitin. In addition, $94 \%$ of the isolates were resistant to tetracycline. About half of the isolates were resistant to ampicillin and a range of $37-47 \%$ was resistant to amoxicillin, piperacillin, and carbenicillin. Twenty percent of the isolates were resistant to ticarcillin. The percentage of the isolates that was resistant to cefotaxime and ceftazidime was eight percent and $18 \%$ respectively. Moreover, only two percent of the isolates were resistant to amoxicillin-clavulanic acid. A higher percentage of the isolates within the carcass samples than within the caeca samples were resistant to the antimicrobial agents used except for cefamandole and tetracycline. Table 1 shows the total resistance of the isolates to the antimicrobial agents including resistance among the carcass and caeca isolates.

\begin{tabular}{|c|c|c|c|c|c|}
\hline \multirow{2}{*}{ Classes of antibiotic } & \multirow{2}{*}{$\begin{array}{l}\text { Subclass of } \\
\text { antibiotic }\end{array}$} & \multirow{2}{*}{ Antibiotic } & \multirow{2}{*}{$\begin{array}{c}\text { Percentage of } \\
\text { resistant } \\
\text { Campylobacter }(\%)\end{array}$} & \multicolumn{2}{|c|}{ Source (\%) } \\
\hline & & & & Carcass & Caeca \\
\hline \multirow[t]{5}{*}{ Penicillin } & \multirow[t]{2}{*}{ Aminopenicillin } & Ampicillin & 49 & 62 & 45 \\
\hline & & Amoxicillin & 47 & 69 & 40 \\
\hline & Ureidopenicillin & Piperacillin & 45 & 62 & 40 \\
\hline & \multirow{2}{*}{ Carboxypenicillin } & Carbenicillin & 37 & 62 & 29 \\
\hline & & Ticarcillin & 20 & 23 & 18 \\
\hline $\begin{array}{l}\beta \text {-Lactam/ } \beta \text {-lactamase } \\
\text { inhibitor combina- } \\
\text { tions }\end{array}$ & & $\begin{array}{l}\text { Amoxicillin and } \\
\text { clavulanic acid }\end{array}$ & 2 & 8 & 0 \\
\hline \multirow[t]{5}{*}{ Cephems } & $\begin{array}{c}\text { First generation Cephalo- } \\
\text { sporin }\end{array}$ & Cephalothin & 100 & 100 & 100 \\
\hline & $\begin{array}{c}\text { Second generation Cepha- } \\
\text { losporin }\end{array}$ & Cefamandole & 98 & 92 & 100 \\
\hline & \multirow{2}{*}{$\begin{array}{c}\text { Third generation Cepha- } \\
\text { losporin }\end{array}$} & Cefotaxime & 8 & 15 & 5 \\
\hline & & Ceftazidime & 18 & 31 & 13 \\
\hline & Cephamycin & Cefoxitin & 98 & 100 & 97 \\
\hline Monobactam & & Aztreonam & 100 & 100 & 100 \\
\hline Tetracyclines & & & 94 & 92 & 95 \\
\hline
\end{tabular}

Table 1: Total resistance of Campylobacter isolates to the antimicrobial agents including resistance among the carcass and caeca isolates.

All isolates were resistant to four or more antimicrobial agents. Among the isolates received, $43 \%$ were resistant to five antimicrobial agents. The antimicrobial resistance pattern in these isolates was identical. Additionally, $29 \%$ and $16 \%$ of the isolates were resistant to nine and ten antimicrobial agents respectively. Among these isolates, a high percentage exhibited a specific resistance pattern to the antimicrobial agents. Resistance to four and seven antimicrobial agents was observed in four percent (each) of the isolates; the patterns of resistance were different. Additionally, two percent of isolates showed resistance to six and eleven antimicrobial agents (each). Moreover, Campylobacter isolates identified in carcass and caeca samples or several caeca samples from the same individual animal did not always have similar resistance profile (Table $2 b$ ). Table 2a shows the antimicrobial resistance patterns of the isolates. Table $2 \mathrm{~b}$ shows the resistance profile of the caeca and carcass isolates obtained from the same individual chicken samples.

\begin{tabular}{|c|c|c|c|c|}
\hline \multirow{2}{*}{$\begin{array}{c}\text { Number of Antibiotics } \\
\text { to which isolates are } \\
\text { resistant }\end{array}$} & \multirow{2}{*}{$\begin{array}{l}\text { Number of isolates that are } \\
\text { resistant (RAPD cluster) }\end{array}$} & \multirow{2}{*}{ Pattern } & \multicolumn{2}{|c|}{ Source } \\
\hline & & & CBcass (RAPD cluster) & Caeca (RAPD cluster) \\
\hline \multirow[t]{2}{*}{4} & 1 (Type H) & $\begin{array}{c}\text { Pattern 1: KF, MA, } \\
\text { ATM, FOX, }\end{array}$ & - & 1 \\
\hline & 1 (Type H) & $\begin{array}{l}\text { Pattern 2: KF, MA, } \\
\text { ATM, TET }\end{array}$ & - & 1 \\
\hline 5 & $\begin{array}{c}22 \text { (12 Type H, } 5 \text { Type F, } 1 \\
\text { Type C, 1Type A, } 3 \text { Type D) }\end{array}$ & $\begin{array}{l}\text { KF, MA, ATM, FOX, } \\
\text { TET. }\end{array}$ & $\begin{array}{c}4 \text { (1 Type } H, 1 \text { Type } C \text {, } \\
\text { 1Type A, } 1 \text { Type D) }\end{array}$ & $\begin{array}{c}18 \text { (11 Type H, } 5 \text { Type F, } \\
\text { 2 Type D) }\end{array}$ \\
\hline 6 & $1($ Type F) & $\begin{array}{l}\text { Pattern 1: AMP, KF, } \\
\text { MA, ATM, FOX, TET }\end{array}$ & - & 1 \\
\hline \multirow[t]{2}{*}{7} & 1 (Type H) & $\begin{array}{c}\text { Pattern 1: AMP, TIC, } \\
\text { KF, MA, ATM, FOX, } \\
\text { TET }\end{array}$ & - & 1 \\
\hline & 1 (Type H) & $\begin{array}{c}\text { Pattern 2: AMP, CB, } \\
\text { KF, MA, ATM, FOX, } \\
\text { TET }\end{array}$ & - & 1 \\
\hline
\end{tabular}




\begin{tabular}{|c|c|c|c|c|}
\hline \multirow[t]{5}{*}{9} & $\begin{array}{c}11 \text { (2 Type F, } 4 \text { Type C, 3Type } \\
\text { G, } 1 \text { Type I) }\end{array}$ & $\begin{array}{l}\text { Pattern 1: AMP, AMX, } \\
\text { CB, PIP, KF, MA, ATM, } \\
\text { FOX, and TET }\end{array}$ & 3 ( 1Type G, 1 Type I) & $\begin{array}{c}8 \text { (2 Type F, } 4 \text { Type } C, 2 \\
\text { Type } G \text { ) }\end{array}$ \\
\hline & 1 (Тype B) & $\begin{array}{c}\text { Pattern 2: AMX, CB, } \\
\text { PIP, KF, MA, CTX, } \\
\text { CAZ, ATM, FOX }\end{array}$ & - & 1 \\
\hline & 1 (Type H) & $\begin{array}{c}\text { Pattern 3: AMP, } \\
\text { AMX, AMC, CB, KF, } \\
\text { MA, ATM, FOX, and } \\
\text { TET }\end{array}$ & 1 & - \\
\hline & 1 (Type H) & $\begin{array}{l}\text { Pattern 4: AMP, } \\
\text { AMX, CB } \\
\text { PIP, TIC, KF, ATM, } \\
\text { FOX, and TET }\end{array}$ & 1 & - \\
\hline & 1 (Type H) & $\begin{array}{c}\text { Pattern 5: AMP, } \\
\text { AMX, PIP, TIC, KF, } \\
\text { MA, ATM, FOX, and } \\
\text { TET }\end{array}$ & - & 1 \\
\hline \multirow[t]{4}{*}{10} & 5 (1Type A, 2 Type E, 1 Type I) & $\begin{array}{c}\text { Pattern 1: AMP, } \\
\text { AMX, PIP, TIC, KF, } \\
\text { MA, CAZ, ATM, FOX, } \\
\text { and TET }\end{array}$ & 1 (Тype A) & 4 (2 Type E, 1 Type I) \\
\hline & 1 (Type A) & $\begin{array}{l}\text { Pattern 2: AMP, } \\
\text { AMX, CB } \\
\text { PIP, TIC, KF, MA, } \\
\text { CAZ, ATM, FOX }\end{array}$ & 1 & - \\
\hline & 1 (Type A) & $\begin{array}{c}\text { Pattern 3: AMX, CB, } \\
\text { PIP, KF, MA, CTX, } \\
\text { CAZ, ATM, FOX, and } \\
\text { TET }\end{array}$ & 1 & - \\
\hline & 1 (Type H) & $\begin{array}{c}\text { Pattern 4: AMP, } \\
\text { AMX, CB } \\
\text { PIP, TIC, KF, MA, } \\
\text { ATM, FOX, and TET }\end{array}$ & - & 1 \\
\hline 11 & 1 (Туре B) & $\begin{array}{l}\text { AMP, AMX, CB, PIP, } \\
\text { KF, MA, CTX, CAZ, } \\
\text { ATM, FOX, and TET. }\end{array}$ & 1 & - \\
\hline
\end{tabular}

Table 2a: The number of Campylobacter isolates, sub-grouped to caeca and carcass, resistant to four or more antimicrobial agents and the patterns of resistance of each. (The numbers in the brackets represent the number of isolates in each cluster). AMP: Ampicillin, AMX: Amoxicillin; CB: Carbenicillin; PIP: Piperacillin; KF: Cephalothin; MA: Cefamandole; CTX: Cefotaxime; CAZ: Ceftazidime; ATM: Aztreonam; FOX: Cefoxitin; TET: Tetracycline; TIC: Ticarcillin; AMC: Amoxicillin and clavulanic acid.

\begin{tabular}{|l|c|c|c|}
\hline \multicolumn{2}{|c|}{$\begin{array}{c}\text { Isolates from the same } \\
\text { chicken sample }\end{array}$} & \multicolumn{2}{|c|}{$\begin{array}{c}\text { Number of Antimicrobial agents to which the isolates were resistant } \\
\text { to/Pattern* }\end{array}$} \\
\hline Caeca & Carcass & Caeca & Carcass \\
\hline 1 & 1 & 9 Pattern 2 & 10 Pattern 3 \\
\hline 1 & 1 & 9 Pattern 1 & 9 Pattern 1 \\
\hline 4 & 1 & 10 Pattern 1 & 10 Pattern 1 \\
\hline 8 & 1 & $\begin{array}{r}7 \text { isolates: resistant to 9 antibiotics Pattern 1, 1 isolate: } \\
\text { resistant to 5 antibiotics Pattern 1 }\end{array}$ & 9 Pattern 1 \\
\hline 8 & 1 & $\begin{array}{r}\text { 7 isolates: resistant to 5 antibiotics Pattern 1, 1 isolate: } \\
\text { resistant to 6 antibiotics Pattern 1 }\end{array}$ & 5 Pattern 1 \\
\hline 2 & 0 & 7 Pattern1 and 2 & - \\
\hline 8 & 0 & 5 Pattern 1 & - \\
\hline 4 & 0 & $\begin{array}{r}\text { 2 isolate: resistant to 5 antibiotics Pattern 1, 2 isolate: } \\
\text { resistant to 4 antibiotics Pattern 1and 2 }\end{array}$ & - \\
\hline
\end{tabular}

Table 2b: Comparison of the resistance profile of caeca and carcass Campylobacter isolates obtained from the same chicken sample. ${ }^{*}$ Refer to patterns in 2 a. (Each row represents a different animal). 
Detection of the resistance encoding gene

PCR amplification of the $b l a_{\text {OXA-61 }}$ gene showed that $92 \%$ (n: 47) of the Campylobacter isolates were positive for the gene. Additionally, all ampicillin resistant Campylobacter isolates carried the blaoxA-61 gene. However, $84 \%$ (n: 22 ) of the ampicillin sensitive isolates were found positive for the $b l a_{\text {OXA-61 }}$ gene. A higher proportion of the caeca isolates (95\%; $\mathrm{n}: 36)$ showed the presence of the $b l a_{\mathrm{OXA}-61}$ gene than carcass isolates (85\%; n: 11).

PCR results showed that 94\% (n: 48) of the isolates harbored the tet $(0)$ gene. All tetracycline resistant Campylobacter were positive for the tet(0) gene; $98 \%$ (n: 50 ) were located on plasmids. Only one carcass isolate had the gene located on the chromosome. On the other hand, the tetracycline sensitive isolates were negative for the tet(0) gene. Moreover, a similar percentage of carcass and caeca isolates showed the presence of this gene (92\%; n: 12 and 95\%; n: 36 respectively)

\section{RAPD}

RAPD analysis revealed the presence of nine distinct clusters namely A, B, C, D, E, F, G, H, I. The incidence of these clusters were $8 \%, 4 \%, 10 \%, 6 \%, 4 \%, 16 \%, 6 \%, 39 \%$, and $4 \%$ respectively. The most common RAPD type, $\mathrm{H}$, contained 20 isolates which were $55.1 \%$ genomically related; 17 isolates were from caeca and three were from carcass. These isolates were resistant to a range of antimicrobial agents (Table 2a). Two sets of samples which included three (caecal samples) and two isolates (one caeca and one carcass samples) were clonal (Figure 1).

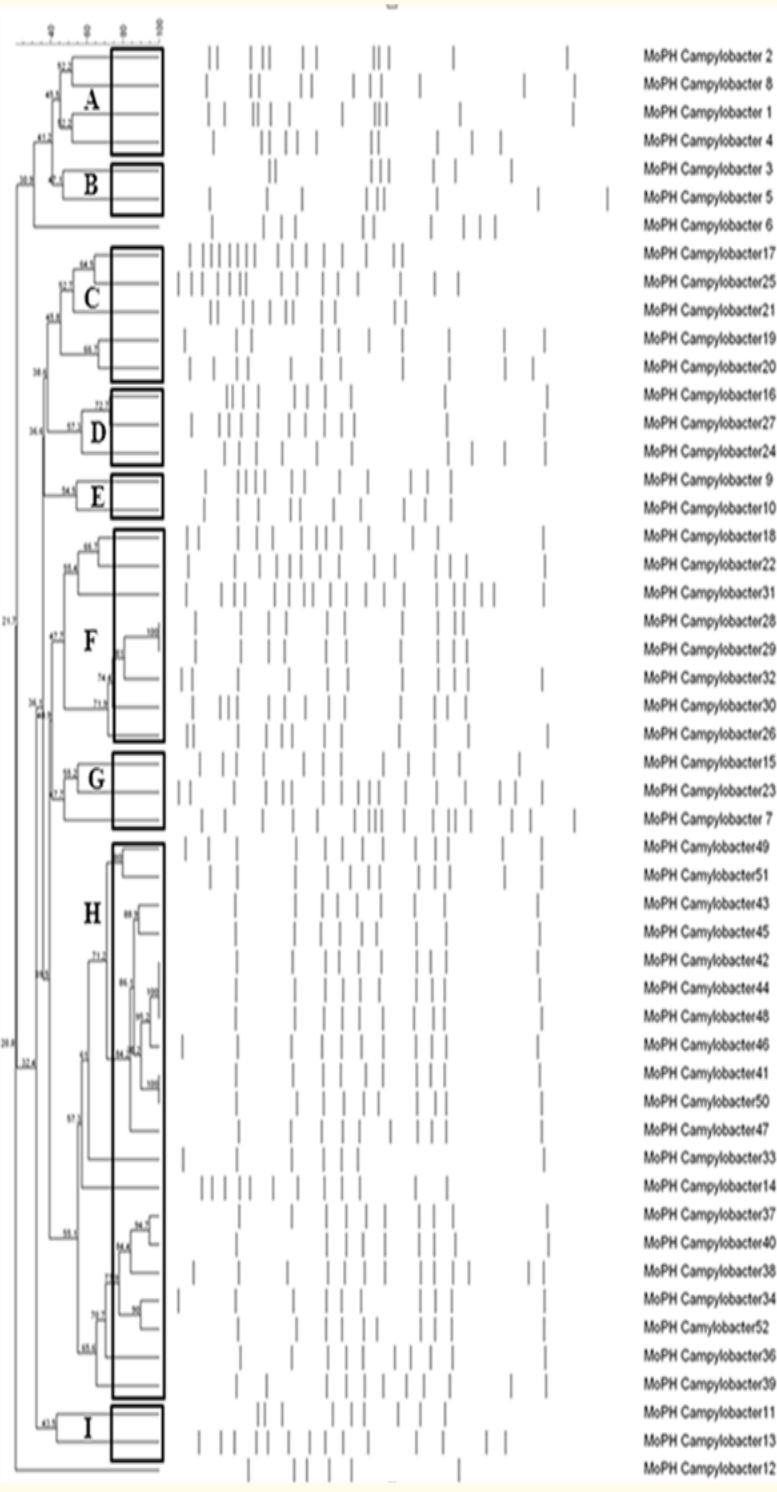

Figure 1: Dendrogram obtained from RAPD analysis of the 51 Campylobacter isolates.
RAPD Type $\mathrm{F}$ included eight isolates having 47.7\% genomic similarity, all of which were derived from caeca. The isolates exhibited three different patterns of antimicrobial resistance (Table 2a). Within this cluster, two isolates were genetically identical (Figure 1). The RAPD Type $\mathrm{C}$ had a genomic relatedness of $45.8 \%$ and included five isolates; four isolates were from caeca and one was from carcass. The majority of these isolates showed resistance to a specific pattern of antimicrobial agents (Table 2a). RAPD Type A included four isolates which were all isolated from carcass and had a genomic similarity of $45.5 \%$. The isolates exhibited a variety of antimicrobial resistance pattern (Table 2a).

RAPD Type D and G had a genomic relatedness of $57.3 \%$ and $47.7 \%$ respectively. They both contained three isolates; two derived from caeca and one from carcass. The isolates in each cluster showed a single antimicrobial resistance pattern (Table 2a).

RAPD Type B, E, and I included two isolates each having a genomic similarity of $47.1 \%, 54.5 \%$, and $43.5 \%$ respectively. The isolates of type $\mathrm{B}$ and I were derived from both caeca and carcass, however that of type $\mathrm{E}$ was derived from caeca only. These isolates showed different antimicrobial resistance patterns (Table 2a). Fig ure 1 shows the dendrogram obtained by RAPD analysis.

\section{Discussion}

Many studies conducted in a number of countries have shown that a significant portion of chicken was contaminated with Campylobacter spp. (Dufrenne et al., 2001; Meldrum et al., 2004; Uyttendaele et al. 1999; Wilson, 2002). Our study showed that the percentage of Campylobacter spp. isolated from poultry was considerable; a higher percentage was isolated from carcass than from caeca samples. Caeca are commonly used for the detection of Campylobacter in poultry; however the carcass can be contaminated with the bacteria (Allen et al., 2007; World organization for animal health, 2008). Moreover, the amount of Campylobacter spp. present on the surface of carcass might change during the processing procedure before getting the final product such as during: scalding defeathering, evisceration, washing, and air or water immersion chilling (Guerin et al., 2010). The cecum of the chicken harbors a large number of Campylobacter species and when this raptures, the bacteria could spread to the carcass (Silva et al., 2011). This could explain why the percentage of Campylobacter in carcass was higher than that in caeca in our study.

Although phenotypic methods for the identification of Campylobacter species are available, these techniques lack standardization and have a limited discriminatory power. A rapid and effective method to identify Campylobacters to the species level is 16S rRNA sequence analysis (Gorkiewicz et al., 2003). In our study, all species of the Campylobacter isolates were identified as $C$. coli. In addition, the same species was found in carcass and caeca isolates. Several studies have shown that $C$. jejuni is the most common species found in poultry while $C$. coli is the predominant species isolated from pigs. However, $C$. coli species can still be found in chicken isolates, even if not as much as C. jejuni (FDA, 2010; Reich et al., 2008; Saenz et al. 2000; World organization for animal health, 2008). Moreover a study by Talhouk., et al. (1998) is in accordance with our study in which $C$. coli was isolated more than $C$. jejuni in chicken carcass and caeca. Similarly, $C$. coli were identified more commonly than was $C$. jejuni from broiler chickens in Italy (Pezzotti et al., 2003) turkey breast specimens from Washington, (Zhao et al., 2001), and commercial chicken livers in Chile (Fernández and Pisón, 1996) On another note, a study done by Allen., et al. (2007) showed that the same species found in the caecal contents was also isolated on the carcass which is in line with our study. 
A large number of the isolates (38/51) showed a single pattern of resistance to a panel of antimicrobial agents. Additionally, isolates from caecal and carcass samples from the same individual animals did not always show the same resistant pattern. Environmental stress during processing procedures such as storage conditions may have played a role in the selection of resistance profiles in these isolates. Campylobacters are usually considered to be resistant to $\beta$-lactam drugs including penicillins and first and second generation cephalosporin. Additionally, they show moderate resistance to third generation cephalosporin such as ceftazidime and cefotaxime; however these drugs have been rarely used clinically (Allos and Blaser, n.d; Van der Auwera and Scorneaux, 1985). A study done Dohne., et al. (2012) showed that $C$. coli exhibited moderate resistance to ampicillin. Moreover, Griggs., et al. (2009) showed that the majority of $C$. coli isolates from poultry in the United Kingdom (UK) exhibited resistance to a wide range of antimicrobial agents belonging to pencillins and cephems class (a number of these antimicrobial agents were used in our study). Our study is in-line with some of the results of these studies.

There is a strong correlation between resistance to ampicillin and $\beta$-lactam drugs and the presence of the $b l a_{\text {OXA-61 }}$ gene. Our study showed that all ampicillin resistant isolates and $84 \%$ of ampicillin susceptible isolates harbored the $b l a_{\text {OXA-61 }}$ gene. Various studies carried out in Brazil and the UK indicated that a very high percentage of ampicillin resistant Campylobacter isolates from poultry products carried the $b l a_{\text {OXA-61 }}$ gene (Griggs et al., 2009; Sierra-Arguello et al., 2015). One of the studies also showed that 1) 59\% of ampicillin susceptible isolates carried the $b l a_{\mathrm{OXA}-61}$ gene and 2) the inactivation of this gene resulted in greater susceptibility to several $\beta$-lactam drugs. The presence of $\beta$-lactamase genes is not always linked with resistance to $\beta$-lactams and might have a function other than mediating resistance in Campylobacters, explaining why a wide number of ampicillin susceptible isolates carried the $b l a_{\text {OXA-61 }}$ gene (Griggs et al., 2009).

Tetracycline has been used in the treatment of Campylobacteriosis, however, the trend of resistance is on the rise (Moore et al., 2005; Rahimi et al., 2010). Our study showed that: a very high percentage of samples were resistant to tetracycline, all tetracyclineresistant isolates were positive for the $\operatorname{tet}(0)$ gene with majority encoded on plasmids, and tetracycline sensitive isolates did not carry the tet $(0)$ gene. A report by NARMS indicated that a moderate percentage $(\sim 42-60 \%)$ of $C$. coli isolates from chicken over a period of a decade were resistant to tetracycline (FDA, 2010). Although resistance to tetracycline in Campylobacter is common, its use in animal farms might increase the pool of multidrug resistant strains (Lee et al., 1994). A study done in Kuwait showed that $88 \%$ of tetracycline resistant Campylobacter isolates carried the gene and $56 \%$ of these isolates had the gene located on plasmids (Albert et al., 2009). The location of this gene on conjugative plasmids or chromosomal elements is the main cause for the wide distribution and the rapid transfer of the tet( 0 ) gene without antimicrobial selection pressure in Campylobacter isolates (Avrain et al., 2004).
RAPD as a subtyping tool for Campylobacter spp. has a high discrimination power and good reproducibility and typability (Madden et al., 1996; Nielsen et al., 2000; Wassenaar and Newell, 2000). Although PFGE and RFLP are among the best genotyping methods, they are labor intensive. Therefore, RAPD was chosen in this study for its simplicity and rapidity. Isolates 28 and 29 belonging to cluster $\mathrm{F}$, isolates $42,44,48$, and isolates 41 and 50 , all belonging to cluster $\mathrm{H}$, were identical at the genomic level. Additionally, several isolates in clusters $\mathrm{H}$ and I showed close genomic similarity (> $85 \%$ ). This might indicate that they are closely related epidemiologically and are consistent with a single genetic event such as mutation, insertion, or deletion of DNA (Tenevor et al., 2005). RAPD analysis also showed a wide diversity among the isolates with high genomic heterogeneity. This observation points out to the presence of different types among different animals which is consistent with several studies (Madden et al., 1996; Weijtens et al., 1993). Our results also show that carcass and caeca isolates or two caeca isolates from the same individual animals did not necessarily have the same genotype. This is in contrast with the observation that individual animals are colonized by a single isolate at every sampling site (Madden et al., 1996). Moreover isolates within most clusters had a predominant source, caeca or carcass (all clusters except B and I) and exhibited a prevalent antimicrobial pattern (all except A, B, I).

\section{Conclusion}

In conclusion, the study provides an insight about the high prevalence of antimicrobial resistance, detection of their resistance encoding genes, and the significant degree of genomic diversity of Campylobacter coli, in two slaughterhouses present in the Lebanese market. The study 1) emphasizes the need for further investigations to determine the genomic link between Campylobacter spp. detected in animals and humans 2) recommends improved surveillance and stresses the need for implementing strict guidelines and regulations and better inspection procedures during food processing.

\section{Bibliography}

1. European Food Safety Authority. "The European Union summary report on trends and sources of zoonoses, zoonotic agents and food-borne outbreaks in 2011". Euro Surveillance 11.4 (2013): 3129.

2. Lehtopolku M. "Antimicrobial Resistance in Campylobacter jejuni and Campylobacter coli". Finland: University of Turku (2011).

3. World Health Organization. Campylobacter, Fact sheet $N^{\circ} 255$. (2011).

4. Martiny D., et al. "Accuracy of the API Campy System, the Vitek 2 Neisseria-Haemophilus Card and Matrix-Assisted Laser Desorption Ionization Time-of-Flight Mass Spectrometry for the Identification of Campylobacter and Related Organisms". 
Clinical Microbiology and Infection: The Official Publication of the European Society of Clinical Microbiology and Infectious Diseases 17.7 (2011): 1001-1006.

5. Bae W., et al. "Prevalence and antimicrobial resistance of ther mophilic Campylobacter spp. from cattle farms in Washington State". Applied Environmental Microbiology 71.1(2005): 169174.

6. Vlieghe ER., et al. "Trends of norfloxacin and erythromycin resistance of Campylobacter jejuni/Campylobacter coli isolates recovered from international travelers, 1994 to 2006". Journal of Travel Medicine 15.6 (2008): 419-425.

7. Taylor D E and Courvalin P. "Mechanisms of antibiotic resistance in Campylobacter species". Antimicrobial Agents and Chemotherapy 32.8 (1988): 1107-1112.

8. Griggs D J., et al. "Beta-Lactamase-Mediated Beta-Lactam Resistance in Campylobacter Species: Prevalence of Cj0299 (Bla OXA-61) and Evidence for a Novel Beta-Lactamase in C. Jejuni". Antimicrobial Agents and Chemotherapy 53.8 (2009): 3357 3364.

9. Parkhill, J., et al. "The Genome Sequence of the Food-Borne Pathogen Campylobacter Jejuni Reveals Hypervariable Sequences". Nature 403.6770 (2000): 665-668.

10. Wassenaar TM and DG Newell. "Genotyping of Campylobacte Spp". Applied and Environmental Microbiology 66.1 (2000) $1-9$

11. Nielsen E M., et al. "Evaluation of Phenotypic and Genotypic Methods for Subtyping Campylobacter Jejuni Isolates from Humans, Poultry, and Cattle". Journal of Clinical Microbiology 38.10 (2000): 3800-3810.

12. Talhouk RS., et al. "Prevalence, Antimicrobial Susceptibility and Molecular Characterization of Campylobacter Isolates Recovered from Humans and Poultry in Lebanon". Le Journal Medical Libanais.The Lebanese Medical Journal 46.6 (1998): 310-316

13. Lane DJ. "16S/23S rRNA sequencing. In: Nucleic acid techniques in bacterial systematics". Stackebrandt, E, and Goodfellow M, eds., John Wiley and Sons, New York, NY (1991): 115175

14. Turner S., et al. "Investigating deep phylogenetic relationships among cyanobacteria and plastids by small subunit rRNA sequence analysis". The Journal of Eukaryotic Microbiology 46.4 (1999): 327-338.

15. Clinical and Laboratory Standards Institute. "Methods for Dilution Antimicrobial Susceptibility for Bacteria that Grow Aerobically"; Approved Standard, $8^{\text {th }}$ edition. CLSI Documen M07-A8. Wayne, PA: CLSI (2009).

16. Pratt A and V Korolik. "Tetracycline Resistance of Australian Campylobacter Jejuni and Campylobacter Coli Isolates". The Journal of Antimicrobial Chemotherapy 55.4 (2005): 452-460.

17. Dufrenne J., et al. "Quantification of the contamination of chicken and chicken products in The Netherlands with Salmonella and Campylobacter". Journal of Food Protection 64.4 (2001): 538-541.

18. Meldrum R J., et al. "Baseline rates of Campylobacter and Salmonella in raw chicken in Wales, United Kingdom, in 2002" Journal of Food Protection 6.7 (2004): 1226-1228.

19. Uyttendaele M., et al. "Incidence of Salmonella, Campylobacter jejuni, Campylobacter coli, and Listeria monocytogenes in poultry carcasses and different types of poultry products for sale on the Belgian retail market". Journal of Food Protection 62.7 (1999): 735-740.

20. Wilson IG. "Salmonella and Campylobacter contamination of raw retail chickens from different producers: a sixyear survey". Epidemiology and Infection 129.3 (2002): 635-636.
21. Allen VM., et al. "Campylobacter Spp. Contamination of Chicken Carcasses during Processing in Relation to Flock Colonisation". International Journal of Food Microbiology 113.1 (2007): 54-61.

22. Allos BM and Blaser MJ. "Campylobacter species. Infectious Disease and Antimicrobial agents database, Pittsburgh. Antimicrobe website" (2015).

23. Albert MI., et al. "Tetracycline Resistance is Frequent among Campylobacter Jejuni Isolates from Kuwait". Microbial Drug Resistance (Larchmont, N.Y.) 15.2 (2009): 115-120.

24. Avrain L., et al. "Evidence for Natural Horizontal Transfer of tetO Gene between Campylobacter Jejuni Strains in Chickens". Journal of applied microbiology 97.1 (2004): 134-40.

25. Dohne S., et al. "Antibiotic susceptibility of Salmonella, Campylobacter coli, and Campylobacter jejuni isolated from Northern German fattening pigs". Journal of Food Protection 75.10 (2012): 1839-1845.

26. European Food Safety Authority. "The European Union Summary Report on antimicrobial resistance in zoonotic and indicator bacteria from humans, animals and food in 2010". Euro Surveilliance 10.3 (2012): 2598.

27. Food and Drug Administration. "National antimicrobial resistance monitoring system executive report". Rockville, MD: U.S. Department of Health and Human Services, Food and Drug Administration. FDA.

28. Fernandez $\mathrm{H}$ and Pison V. "Isolation of thermotolerant species of Campylobacter from commercial chicken livers". International Journal of Food Microbiology 29.1 (1996): 75-80.

29. Gorkiewicz G., et al. "Species-Specific Identification of Campylobacters by Partial 16S rRNA Gene Sequencing". Journal of Clinical Microbiology 41.6 (2003): 2537-2546.

30. Guerin M T., et al. "The Change in Prevalence of Campylobacter on Chicken Carcasses during Processing: A Systematic Review". Poultry Science 89.5 (2010): 1070-1084.

31. Lee C Y., et al. "Occurrence of Plasmids and Tetracycline Resistance among Campylobacter Jejuni and Campylobacter Coli Isolated from Whole Market Chickens and Clinical Samples". International Journal of Food Microbiology 24.1-2 (1994): 161-70.

32. Madden RH., et al. "Sub-Typing of Animal and Human Campylobacter Spp. using RAPD". Letters in Applied Microbiology 23.3 (1996): 167-170.

33. Moore J E., et al. "Campylobacter". Veterinary Research 36.3 (2005): 351-38.

34. Pezzotti G., et al. "Occurrence and resistance to antibiotics of Campylobacter jejuni and Campylobacter coli in animals and meat in northeastern Italy". International Journal of Food Microbiology 82.3 (2003): 281-287.

35. Rahimi E., et al. "Prevalence and Antimicrobial Resistance of Campylobacter Species Isolated from Chicken Carcasses during Processing in Iran". Poultry science 89.5 (2010): 10151020.

36. Reich F., et al. "The Effects of Campylobacter Numbers in Caeca on the Contamination of Broiler Carcasses with Campylobacter". International Journal of Food Microbiology 127.1-2 (2008): 116-120.

37. Saenz Y., et al. "Antibiotic resistance in Campylobacter strains isolated from animals, foods, and humans in Spain in 1997 1998". Antimicrobial Agents and Chemotherapy 44.2 (2000): 267-271.

38. Silva J., et al. "Campylobacter Spp. as a Foodborne Pathogen: A Review". Frontiers in Microbiology 2 (2011): 200 
39. Sierra-Arguello $Y$ M., et al. "Resistance to $\beta$-lactam and tetracycline in Campylobacter spp. isolated from broiler slaughterhouses in southern Brazil". Pesquisa Veterinária Brasileira 35.7 (2015): 637-642.

40. Tenover F C., et al. "Interpreting Chromosomal DNA Restriction Patterns Produced by Pulsed-Field Gel Electrophoresis: Criteria for Bacterial Strain Typing". Journal of Clinical Microbiology 33.9 (1995): 2233-2239.

41. Van der Auwera P and Scorneaux B. "In vitro susceptibility of Campylobacter jejuni to 27 antimicrobial agents and various combinations of beta-lactams with clavulanic acid or sulbactam". Antimicrobial agents and chemotherapy 28.1 (1985): 37-40.

42. Weijtens M J., et al. "Prevalence of Campylobacter in pigs during fattening; an epidemiological study". The veterinary Quarterly 15.4 (1993): 138-143.

43. World organization for animal health. 'Campylobacter jejuni and Campylobacter coli. OIE Terrestrial Manual chapter 2.9.3, France (2008).

44. Zhao C., et al. "Prevalence of Campylobacter Spp., Escherichia Coli, and Salmonella Serovars in Retail Chicken, Turkey, Pork, and Beef from the Greater Washington, D.C., Area". Applied and Environmental Microbiology 67.12 (2001): 54315436.

\section{Volume 1 Issue 4 April 2018}

(c) All rights are reserved by Ghassan M Matar., et al. 